\title{
ANALYTICAL SOLUTION OF BEAMS ON ELASTIC FOUNDATION
}

\author{
*Sungat Akhazhanov ${ }^{1}$, Nazgul Omarbekova² ${ }^{2}$ Assel Mergenbekova², Gulzat Zhunussova ${ }^{2}$ and \\ Damesh Abdykeshova ${ }^{2}$
}

${ }^{1}$ Buketov Karaganda State University, Kazakhstan; ${ }^{2}$ Karaganda Medical University, Kazakhstan

*Corresponding Author, Received: 06 April 2020, Revised: 21 April 2020, Accepted: 29 April 2020

\begin{abstract}
The paper deals with a new manner of obtaining an analytical solution of the problem of bending of a beam on an elastic foundation. In the design of such structures, to describe the foundation response to applied loads, the mechanical model of Winkler is often used, for almost one and a half century. However, it has some shortcomings, mainly because it assumes no interaction between the adjacent springs and thus neglects the vertical shearing stress that occurs within subgrade materials. In this paper proposes a felicitous approach for solving the equilibrium equation and applying the boundary conditions, used to static analysis of beams resting on elastic foundations, is presented as an alternative to the classical Winkler and Vlasov models. The resolving equation of bending of a beam on an elastic foundation is obtained. The account of the elastic foundation is produced by means of parameter of flexural stiffness. This idealization provides much more information on the stress and deformation within soil mass compared to the well-known Winkler model, and it has the important advantage of eliminating the necessity of arbitrarily determining the values of the foundation parameters. The solutions of sample problems, obtained by using the new analytical model, are compared with results obtained by the Winkler and Vlasov models.
\end{abstract}

Keywords: beams, elastic foundations, Winkler model, Vlasov model, present model

\section{INTRODUCTION}

In geotechnical engineering, there are numerous situations where the designer has to use simple empirical procedures to size the footings to transfer the loads from the superstructure to the soil underneath. While spot footings are designed using an allowable bearing value approach, most engineers adopt a similar technique for the design of continuous footings also. When the continuous footings carry distributed and concentrated loads, the computation of the vertical displacements of the footing along the longitudinal direction becomes necessary to evaluate the possible differential settlements of the footing. If we assume that the continuous footing acts like a beam, then its analysis can be done using the concept of a beam on elastic foundation. Depending on the longitudinal stiffness of the beam, the loads on the beam are distributed from the beam and into the soil in a very complex manner. In other words, the behavior of the beam due to the loads depends on the material properties of the soil as well as its own stiffness characteristics. Such problems are called soilstructure interaction problems, and the beam on elastic foundation problem is one of them.

The concept of beam on elastic foundation is mathematically elegant; however, it is difficult to come up with the parameters that represent the behavior of the soil. The problem becomes extremely complex, when the deformation in the soil becomes elastic and partly plastic.

The model consists of an elastic beam (Euler beam) resting on a linearly elastic soil medium. This concept has been extensively used by railroad engineers for many years, in order to design the railroad tracks. In the past, research has been undertaken to construct analytical models of beams on elastic foundations [1]. A review of foundation models was performed by Dutta and Roy [2]. Most probably, the oldest model used to simulate beams on elastic foundations is the Winkler model [3]. He assumed the soil to have linear elastic behavior, such that the pressure on the surface is proportional to the deflection of the soil surface in the region of the load. Since the foundation soil in the Winkler model is described by vertical springs only, we find that they carry the vertical loads without any mutual interaction. In other words, these springs are unable to represent the shear stresses in the subsoil. Shear stresses are developed in the subsoil if the vertical displacements between adjacent springs vary. One can see that if a uniform beam with free ends carries a uniformly distributed load, the solution obtained from the Winkler model is a rigid body displacement. In other words, the calculation will indicate that there is no bending moment in the beam. In reality, there will be some edge shear forces resisting the deformation of the soil which makes the beam to deform in a curved deflected 
shape, unless the beam is infinitely rigid. Realizing the inconsistency in the Winkler model which is a one parameter model, Pasternak [4] and Filonenko-Borodich [5] developed a twoparameter model, in which the connectivity of the continuum behavior was considered. Vlasov and Leontiev [6] enhanced the theory of the twoparameter model by using a variational approach. Since most subsoil conditions can be approximated by having a relatively hard soil layer or rock at a finite depth, they assumed that the subsoil has a finite uniform depth, where the displacements at the bottom are assumed to be zero. They introduced a function $\gamma$ which defines the distribution of the vertical displacement in the subsoil. The authors did not provide any mechanism for the calculation of $\gamma$. Jones and Xenophontos [7] established a relationship between the parameter $\gamma$ and the displacement characteristics, but did not suggest any method for the calculation of its actual value. Following Jones and Xenophontos, Vallabhan and Das [8] determined the parameter $\gamma$ as a function of the characteristic of the beam and the foundation, using an iterative procedure. They named this model a modified Vlasov model [9].

Even though the Vlasov model was developed as early as 1966, it has not been used by practicing engineers. The Authors considers the following three major reasons for its lack of acceptance in engineering design. The first reason is that one has to estimate the value of $\gamma$ parameter that defines the decay of the vertical displacement in the subsoil. The second reason is that the solutions of the Vlasov equations are rather complex. The third reason is that nobody has compared the solution of the Vlasov model with other more exact solutions.

In this study, an analytical solution of beams on elastic foundation has been developed. The simplified approach for calculation a beams on elastic foundations, is presented.

\section{THE SIMPLIFIED ANALYTICAL MODEL FOR BEAMS ON ELASTIC FOUNDATION}

We will consider a beam having an elastic foundation as a compressible resilient layer in $H$ thick and with the modulus of elasticity for the material $E_{0}$. Between a beam and elastic foundation a complete contact is observed, i.e. a beam works without tearing away and slip. The elastic foundations are assumed to be isotropic and homogeneous. We will present the elastic foundation as a vertical beam (a lower end is restrainted, overhead - free) with next descriptions $(H, A, J)$ :
$A=b_{0} I, J=\frac{b_{0} I^{3}}{12}$,

where, A, $J$ - area and axial moment of inertia for the cross section; I - length of the beam.

Loading this beam by forces ( $k$ - vertical, $m$ horizontal) using the Mohr formula, we find displacement of the given beam's free end:

$W=\frac{k \cdot H}{E_{0} A}, u=\frac{m \cdot H^{3}}{3 E_{0} J}$,

where, $E_{0} A, E_{0} J$ - beam stiffness in compression and bending; $W, u$ - vertical and horizontal displacements beam's free end, $H$ - height of resilient layer (length of vertical beam).

The components of displacement on a classic theory are determined as follows [10]:

$$
\begin{aligned}
& u_{1}\left(x_{1}, x_{3}\right)=-h \cdot z \frac{d W}{d x_{1}}, \\
& u_{3}\left(x_{1}, x_{3}\right)=W\left(x_{1}\right), \quad z=\frac{x_{3}}{h},
\end{aligned}
$$

where, $W\left(x_{1}\right)$ - function of bending of beam; $u_{1}, u_{3}$ - displacement of points, directed along coordinate axes $x_{1}$ and $x_{3} ; h$ - height of beam.

Taking into account displacement of beam (3) and condition of complete contact, from (2) we determine force factors

$k=\frac{E_{0} A}{H} W, m=-\frac{3}{2} \frac{E_{0} J}{H^{3}} \cdot h \frac{d W}{d x_{1}}$

To unify the mathematical model of beam we will consider the external load as

$\bar{q}\left(x_{1}\right)=q\left(x_{1}\right)-P \frac{d^{2} W}{d x_{1}^{2}}+\sigma \cdot W$,

where, $q\left(x_{1}\right)$ - normal external load; $P$ - factor, owning a dimension of force; $\sigma$ - factor, owning a dimension of stress.

Now we will determine factors involved in (5). Comparing (5) and (4) and taking into consideration that $P$ is force, $\sigma$ is stress, we determine their values

$\sigma=\frac{k}{\mathrm{l}}=\frac{E_{0} A}{\mathrm{I} \cdot H}, P=\frac{3}{2} \frac{E_{0} J h}{H^{3}}$ 
Parameter of the moment of inertia for the cross section of the beam determined as follows [11]:

$$
\begin{aligned}
& g=1+\frac{K_{N}}{K_{N}^{0}}+\frac{K_{\theta}}{K_{\omega}}, \\
& K_{N}=\frac{P l^{2}}{E J_{0}}, K_{\theta}=\frac{\sigma{ }^{2}}{E J_{0}}
\end{aligned}
$$

Introducing (6) into (7), we will find value of parameter of the moment of inertia of the cross section of the beam on elastic foundation:

$$
\begin{aligned}
& g=1+\frac{K_{N}}{K_{N}^{0}}+\frac{K_{\theta}}{K_{\omega}}, \\
& K_{N}=\frac{3}{2}\left(\frac{E_{0} J}{E J_{0}}\right) \frac{h \mathrm{l}^{2}}{H^{3}}=\frac{3}{2} \frac{E_{0}}{E} \frac{\mathrm{I}^{5}}{H^{3} h^{2}}, \\
& K_{\theta}=\left(\frac{E_{0} A l^{2}}{E J_{0}}\right) \frac{\mathrm{I}}{H}=12 \frac{E_{0}}{E} \frac{\mathrm{I}^{4}}{H h^{3}},
\end{aligned}
$$

where the relation between elastic foundation stiffness and bending beam stiffness are shown in brackets.

Parameters $K_{N}^{0}$ and $K_{\omega}$ are defined as follows [11]:

- for hinged beam $K_{N}^{0}=\pi, K_{\omega}=\pi^{4}$;

- for fixed-end beam $K_{N}^{0}=4 \pi^{2}, K_{\omega}=(4,73)^{4}$;

- for cantilever beam $K_{N}^{0}=\frac{\pi^{2}}{4}, K_{\omega}=(1,875)^{4}$;

- for beam built in at one end and supported at the other $K_{N}^{0}=(4,493)^{2}, K_{\omega}=(3,927)^{4}$.

To justify the obtained parameter (8), we use the classical (technical) theory of beam bending on an elastic foundation:

- hypotheses and components of displacements

$\varepsilon_{3}=0, \gamma_{13}=0, \sigma_{3}=0$,

$\varepsilon_{3}=\frac{\partial u_{3}}{\partial x_{3}}=0: u_{3}\left(x_{1}, x_{3}\right)=W\left(x_{1}\right)$,

$\gamma_{13}=\frac{\partial u_{1}}{\partial x_{3}}+\frac{\partial u_{3}}{\partial x_{1}}=0: u_{1}\left(x_{1}, x_{3}\right)=-h \varphi(z) \frac{d W}{d x_{1}}$,

$x_{3}=z h, \varphi(z)=c+z$,

where, $c$ - arbitrary constant to be determined; $\mathrm{z}$ dimensionless transversal coordinate.

- deformation components

$$
\varepsilon_{1}=\frac{\partial u_{1}}{\partial x_{1}}=-h \varphi(z) \frac{d^{2} W}{d x_{1}^{2}},
$$

$\varepsilon_{3}=0, \gamma_{3}=0$

- stress components

$$
\begin{aligned}
& \sigma_{1}=-E h \varphi(z) \frac{d^{2} W}{d x_{1}^{2}}, \\
& \tau_{13}=E h^{2}\left(A+c z+\frac{z^{2}}{2}\right) \frac{d^{3} W}{d x_{1}^{3}}, \\
& \sigma_{3}=E h^{3}\left(B-A z-c \frac{z^{2}}{2}-\frac{z^{3}}{6}\right) \frac{d^{4} W}{d x_{1}^{4}},
\end{aligned}
$$

where, $B, A$ - arbitrary constants to be determined.

For these purposes based on (2) and (9) we will find components of stress at $z=-\frac{1}{2}$ :

$$
\begin{aligned}
& \sigma_{3}^{0}=\frac{k}{\mathrm{I}}=\frac{E_{0} A}{\mathrm{I} H} W\left(x_{1}\right), \\
& \tau_{13}^{0}=\frac{m}{\mathrm{I}}=\frac{1}{\mathrm{I}} \frac{3 E_{0} A}{H^{3}} u_{1}\left(x_{1},-\frac{1}{2}\right)= \\
& =-\frac{h}{\mathrm{I}} \frac{3 E_{0} J}{H^{3}}\left(c-\frac{1}{2}\right) \frac{d W}{d x_{1}} .
\end{aligned}
$$

We write the following boundary and contact conditions:

- boundary conditions at $z=\frac{1}{2}$

$$
\begin{aligned}
& \tau_{13}=0: A=-\frac{1}{8}-\frac{c}{2}, \\
& \sigma_{3}=q\left(x_{1}\right): \\
& E h^{3}\left(B-\frac{A}{2}-\frac{c}{8}-\frac{1}{48}\right) \frac{d^{4} W}{d x_{1}^{4}}=q\left(x_{1}\right)
\end{aligned}
$$

- contact conditions at $z=-\frac{1}{2}$

$$
\begin{aligned}
& \tau_{13}=\tau_{13}^{0}: E h^{2}\left(A-\frac{c}{2}+\frac{1}{8}\right) \frac{d^{3} W}{d x_{1}^{3}}=\tau_{13}^{0}, \\
& \frac{12 K_{N}^{0}}{h l^{2}} E J_{0}\left(A-\frac{c}{2}+\frac{1}{8}\right)=\frac{h}{\mathrm{I}} \frac{3 E J_{0}}{H^{3}}\left(c-\frac{1}{2}\right), \\
& \sigma_{3}=\sigma_{3}^{0}: E h^{3}\left(B+\frac{A}{2}-\frac{c}{8}+\frac{1}{48}\right) \frac{d^{4} W}{d x_{1}^{4}}=\sigma_{3}^{0}, \\
& \frac{12 K_{\omega}}{\mathrm{I}^{4}} E J_{0}\left(B+\frac{A}{2}-\frac{c}{2}+\frac{1}{48}\right)=\frac{E_{0} A}{\mathrm{IH}} .
\end{aligned}
$$

Note that in formula (14) we used following equations [11].

$$
\begin{aligned}
& E J_{0} \frac{d^{4} W}{d x_{1}^{4}}+N \frac{d^{2} W}{d x_{1}^{2}}=0, \quad K_{N}^{0}=\frac{N l^{2}}{E J_{0}}, \\
& E J_{0} \frac{d^{4} W}{d x_{1}^{4}}-\rho h \omega^{2} W=0, \quad K_{\omega}=\frac{\left.\rho h \omega^{2}\right|^{4}}{E J_{0}},
\end{aligned}
$$


where, (15) - is stability equations of a bar; (16) is free-vibration equations of a bar; $N$ compressive force; $\rho, h, \omega$ - density, height and free-vibration frequency of a beam.

Introducing the following designations:

$m_{0}=\frac{1}{4} \frac{E_{0} J}{E J_{0}} \frac{h^{2} \mathrm{I}}{H^{3}} \frac{1}{K_{N}^{0}}, n_{0}=\frac{1}{12} \frac{E_{0} A \mathrm{l}^{2}}{E J_{0}} \frac{\mathrm{I}}{H} \frac{1}{K_{\omega}}$

From first condition of (13) and (14) we find arbitrary constants

$$
\begin{aligned}
& c=\frac{1}{2} \frac{m_{0}}{\left(1+m_{0}\right)}, A=-\frac{1}{8}-\frac{c}{8}, \\
& B=\frac{1}{24}+n_{0}+\frac{3}{8} c
\end{aligned}
$$

From second condition of (13) considering (18) we will come up with equation defining $W\left(x_{1}\right)$ :

$$
E J_{0} g \frac{d^{4} W}{d x_{1}^{4}}=q\left(x_{1}\right), g=1+12 n_{0}+6 c
$$

If we consider in (18) $c=m_{0}$, then after introducing (17) into (19) we get value - $g$, coinciding with (8). It means that the technique used in obtaining (8) is correct, but this parameter $g$ will be approximate in comparison with the exact one in (19).

Based on (18) stress components of (11) will change as:

$$
\begin{aligned}
& \sigma_{1}=-E h \varphi(z) \frac{d^{2} W}{d x_{1}^{2}}, \tau_{13}=-\frac{E h^{2}}{8} \varphi(z) \frac{d^{3} W}{d x_{1}^{3}}, \\
& \sigma_{3}=E J_{0} \delta(z) \frac{d^{4} W}{d x_{1}^{4}}, \\
& \varphi(z)=c+z, \psi(z)=\left(1-4 z^{2}\right)+4 c(1-2 z), \\
& \delta(z)=\left(\frac{1}{2}+\frac{3}{2} z-2 z^{3}\right)+\frac{3}{2} c\left(3+4 z-4 z^{2}\right)+12 n_{0}
\end{aligned}
$$

The following internal forces and external load correspond to these stresses.

$$
\begin{aligned}
& M=-E J_{0} \frac{d^{2} W}{d x_{1}^{2}}, Q=-E J_{0} g_{0} \frac{d^{3} W}{d x_{1}^{3}}, \\
& q=E J_{0} g \frac{d^{4} W}{d x_{1}^{4}}, \quad g_{0}=1+6 c
\end{aligned}
$$

Considering (21) the equation (20) will be as following

$$
\begin{aligned}
\sigma_{1} & =\frac{h}{J_{0}} \varphi(z) M, \tau_{13}=\frac{h^{2}}{8 J_{0} g_{0}} \psi(z) Q, \\
\sigma_{3} & =\delta(z) \frac{q}{g},
\end{aligned}
$$

where, $g$ is defined by formula (19).

Consider bending function of a beam as follows

$W(x)=\frac{W_{*}}{g} X(x), W_{*}=\frac{q_{0} \mathrm{I}^{4}}{E J_{0}}, x=\frac{x_{1}}{\mathrm{l}}$,

where, $W_{*}$ - bend multiplier; $q_{0}$ - maximum external load intensity; $x$ - dimensionless longitudinal coordinate; $X(x)$ - dimensionless function of bending.

Based on (23), the internal forces and the resolving equation (21) changes as following:

$$
\begin{aligned}
& M=-\frac{M_{0}}{g} X^{\prime \prime}(x), Q=-\frac{g_{0}}{g} Q_{0} X^{\prime \prime \prime}(x), \\
& X^{I V}(x)=P u(x), M_{0}=q_{0} I^{2}, Q_{0}=q_{0} I,
\end{aligned}
$$

where, $P u(x)$ - the law of variation of the external uniform load.

When solving the equation (24) the natural boundary conditions used for the calculation of the constants of integration are

1) hinged

$$
\begin{aligned}
& W=0 \rightarrow X\left(x_{0}\right)=0 \\
& M=-\frac{M_{0}}{g} X^{\prime \prime}\left(x_{0}\right)=0 \rightarrow X^{\prime \prime}\left(x_{0}\right)=0
\end{aligned}
$$

2) fixed-end

$$
\begin{aligned}
& W=0 \rightarrow X\left(x_{0}\right)=0 \\
& \theta=\frac{d W}{d x_{1}}=0 \rightarrow X^{\prime}\left(x_{0}\right)=0
\end{aligned}
$$

3) free

$$
\begin{aligned}
& M=-\frac{M_{0}}{g} X^{\prime \prime}\left(x_{0}\right)=0 \rightarrow X^{\prime \prime}\left(x_{0}\right)=0 ; \\
& Q=-\frac{g_{0}}{g} X^{\prime \prime \prime}\left(x_{0}\right)=0 \rightarrow X^{\prime \prime \prime}\left(x_{0}\right)=0 ;
\end{aligned}
$$

4) with elastic bearings 
$W=\frac{Q b^{3}}{3 E_{*} J_{*}} \rightarrow X\left(x_{0}\right)=\mathrm{m}_{r}^{1} X^{\prime \prime \prime}\left(x_{0}\right)$

$\theta=\frac{M b}{E_{*} J_{*}} \rightarrow \pm X\left(x_{0}\right)=\frac{1}{S} X^{\prime}\left(x_{0}\right)$;

$r=3 \frac{E_{*} J_{*}}{E J_{0}} \frac{\mathrm{I}^{3}}{b^{3}} \frac{g}{g_{0}} ; S=\frac{E_{*} J_{*}}{E J_{0}} \frac{\mathrm{I}}{b} g$,

where, $x_{0}=0,1$ - coordinates of extreme bearing points; $E_{*} J_{*}$ - reinforced beam bending stiffness; $b$ - it's length; $g, g_{0}$ - elastic foundation parameters, defined by formulas (19) and (21); the upper (lower) sign corresponds to the left (right) bearing.

The reactive pressures of the elastic foundation are determined by the formula (12) and according to (23) changes as following

$$
\sigma_{3}^{0}=q_{0}\left\{\begin{array}{l}
-\frac{g_{0}}{g} \frac{X^{\prime \prime \prime}(0)}{\alpha_{1}}+\frac{E_{0} A l^{2}}{E J_{0}} \frac{\mathrm{I}}{H \cdot g} X(x)+ \\
+\frac{g_{0}}{g} \frac{X^{\prime \prime \prime}(1)}{\alpha_{1}}
\end{array}\right\},
$$

where, first and third elements are included only for points $x=0$ and $x=1 ; \alpha_{1}$ - very small number used at replacing shear force by uniform load.

The calculation of any beam on an elastic foundation is carried out according to the following algorithm:

1. The geometric and physical characteristics of: the beam $h, \mathrm{I}, b_{0}, E_{0}$; fixed bearing $H, b, b_{0}, E_{*}$ are set.

2. The law of variation of the external uniform load $P u(x)$ is established.

3. The dimensionless function of bending $X(x)$ is determined by solving equation (24) and satisfying one of the variants of the boundary conditions (25) - (28).

4. The parameters $K_{N}^{0}, K_{\omega}$ corresponding to the boundary conditions of the beam are selected.

5 . Based on the values of parameters (17) and (18), the axial moment of inertia of the cross section $g$ is found by formula (19).

6 . The functions (20) and the internal forces of the beam are found by formula (24).

7. The stress components (22) and displacement components (9) are determined.

8 . The law of reactive pressure change is defined by the formula (29).

\section{ANALYTICAL}

RESULTS

AND ANALYSIS

We will consider the implementation of the calculation algorithm using the following examples.

Even though the continuum mechanics approach may look laborious and difficult to use for a closed-form solution, the analytical model is quite simple and can be easily implemented in application-specific software. An example of such software is MathCad which can handle a wide range of static loading problems involving onedimensional beams supported by one- or twoparameters elastic foundation, for any loading and boundary condition.

\subsection{Example 1}

A beam of length $\mathrm{I}=1 \mathrm{~m}$, width $b_{0}=1 \mathrm{~m}$ and height $h=0.5 \mathrm{~m}$, with modulus of elasticity $E=10000 \mathrm{~Pa}$, is considered to be supported by foundation having depth $H=1 \mathrm{~m}$, deformation modulus $E_{0}=1(10,100) P a$ and Poissons ratio, $v=0.25$. The beam carries external uniform

vertical load, $q=1 \frac{N}{m}$.

The values of the maximum vertical displacements, bending moments and shear forces obtained are shown in Tables 1-4. The detailed analytical solutions are obtained for the uniformly distributed load case. The comparisons of the vertical displacements, bending moments and shear forces of the beam on elastic foundations under uniformly distributed loads using the present model were performed with those by the Winkler and Vlasov models. The comparison results are presented in a series of figures from 1 through 9 . It can be noted that three models have almost the same shape and they are in good agreement. This demonstrate the versatility of the new simplified analytical model for beams on elastic foundation.

Table 1 The Maximum values of uniformly distributed load (Modular Ratio $E_{0} / E=0.0001$ )

\begin{tabular}{cccc}
\hline \multirow{2}{*}{ Property } & \multicolumn{3}{c}{ Case } \\
\cline { 2 - 4 } & $\begin{array}{c}\text { Winkler } \\
\text { Model }\end{array}$ & $\begin{array}{c}\text { Vlasov } \\
\text { Model }\end{array}$ & $\begin{array}{c}\text { Present } \\
\text { Model }\end{array}$ \\
\hline $\begin{array}{c}\text { Max Vertical } \\
\text { displacement }\end{array}$ & 0.000999 & 0.000998 & 0.000999 \\
\hline $\begin{array}{c}\text { Max } \\
\text { Bending } \\
\text { moment }\end{array}$ & 0.1249 & 0.1248 & 0.1249 \\
\hline $\begin{array}{c}\text { Max Shear } \\
\text { force }\end{array}$ & 0.4997 & 0.4992 & 0.4996 \\
\hline
\end{tabular}


Table 2 The Maximum values of uniformly distributed load (Modular Ratio $E_{0} / E=0.001$ )

\begin{tabular}{cccc}
\hline \multirow{2}{*}{ Property } & \multicolumn{3}{c}{ Case } \\
\cline { 2 - 4 } & $\begin{array}{c}\text { Minkler } \\
\text { Model }\end{array}$ & $\begin{array}{c}\text { Vlasov } \\
\text { Model }\end{array}$ & $\begin{array}{c}\text { Present } \\
\text { Model }\end{array}$ \\
\hline $\begin{array}{c}\text { Max Vertical } \\
\text { displacement }\end{array}$ & 0.000992 & 0.000982 & 0.000992 \\
\hline $\begin{array}{c}\text { Max } \\
\text { Bending } \\
\text { moment }\end{array}$ & 0.1239 & 0.1226 & 0.1240 \\
\hline $\begin{array}{c}\text { Max Shear } \\
\text { force }\end{array}$ & 0.4966 & 0.4925 & 0.4961 \\
\hline
\end{tabular}

Table 3 The Maximum values of uniformly distributed load (Modular Ratio $E_{0} / E=0.01$ )

\begin{tabular}{cccc}
\hline \multirow{2}{*}{ Property } & \multicolumn{3}{c}{ Case } \\
\cline { 2 - 4 } & $\begin{array}{c}\text { Winkler } \\
\text { Model }\end{array}$ & $\begin{array}{c}\text { Vlasov } \\
\text { Model }\end{array}$ & $\begin{array}{c}\text { Present } \\
\text { Model }\end{array}$ \\
\hline $\begin{array}{c}\text { Max Vertical } \\
\text { displacement }\end{array}$ & 0.000922 & 0.000841 & 0.000924 \\
\hline $\begin{array}{c}\text { Max } \\
\text { Bending } \\
\text { moment }\end{array}$ & 0.1150 & 0.1047 & 0.1155 \\
\hline $\begin{array}{c}\text { Max Shear } \\
\text { force }\end{array}$ & 0.4685 & 0.4353 & 0.4635 \\
\hline
\end{tabular}

Table 4 The Maximum values of uniformly distributed load (Modular Ratio $E_{0} / E=0.1$ )

\begin{tabular}{cccc}
\hline \multirow{2}{*}{ Property } & \multicolumn{3}{c}{ Case } \\
\cline { 2 - 4 } & $\begin{array}{c}\text { Winkler } \\
\text { Model }\end{array}$ & $\begin{array}{c}\text { Vlasov } \\
\text { Model }\end{array}$ & $\begin{array}{c}\text { Present } \\
\text { Model }\end{array}$ \\
\hline $\begin{array}{c}\text { Max Vertical } \\
\text { displacement }\end{array}$ & 0.000541 & 0.000459 & 0.000549 \\
\hline $\begin{array}{c}\text { Max } \\
\text { Bending } \\
\text { moment }\end{array}$ & 0.0661 & 0.0587 & 0.0687 \\
\hline $\begin{array}{c}\text { Max Shear } \\
\text { force }\end{array}$ & 0.3144 & 0.2695 & 0.2830 \\
\hline
\end{tabular}

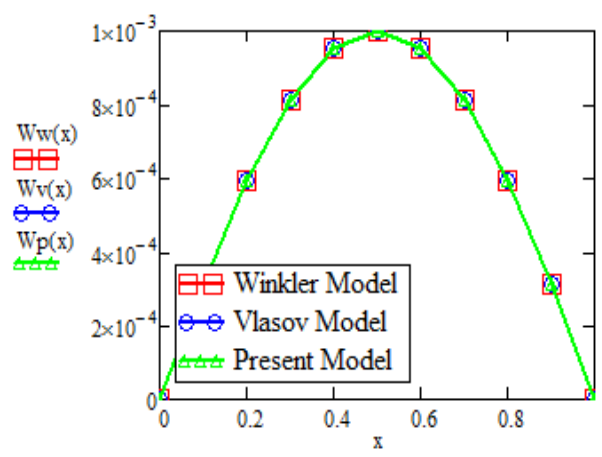

Fig. 1 Vertical displacement of the beam on elastic foundation (Modular Ratio $E_{0} / E=0.0001$ )

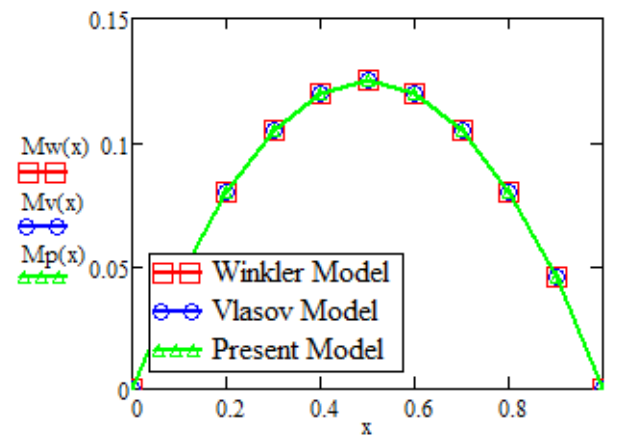

Fig. 2 Bending moment of the beam on elastic foundation (Modular Ratio $E_{0} / E=0.0001$ )

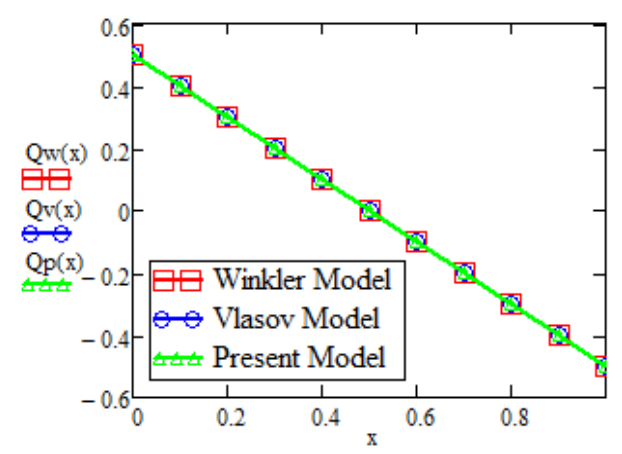

Fig. 3 Shear force of the beam on elastic foundation (Modular Ratio $E_{0} / E=0.0001$ )

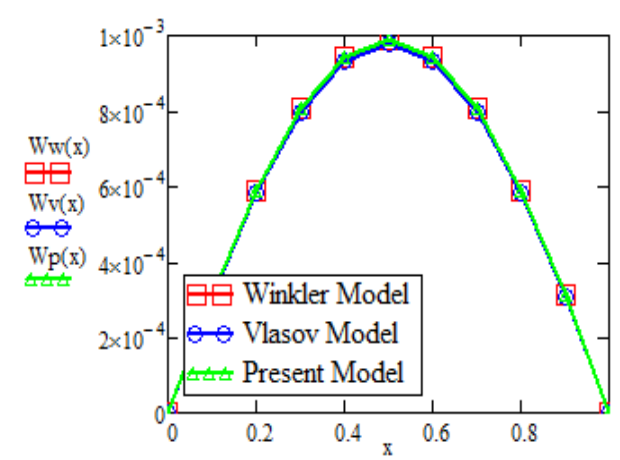

Fig. 4 Vertical displacement of the beam on elastic foundation (Modular Ratio $E_{0} / E=0.001$ )

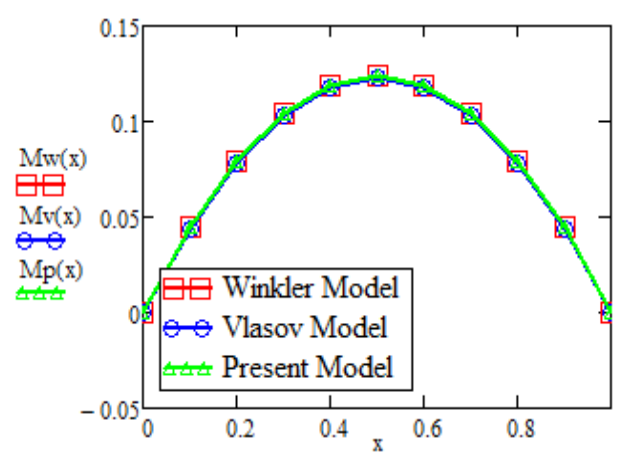

Fig. 5 Bending moment of the beam on elastic foundation (Modular Ratio $E_{0} / E=0.001$ ) 


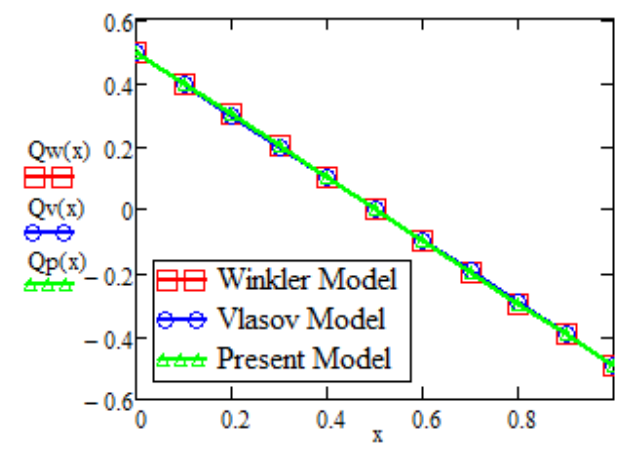

Fig. 6 Shear force of the beam on elastic foundation (Modular Ratio $E_{0} / E=0.001$ )

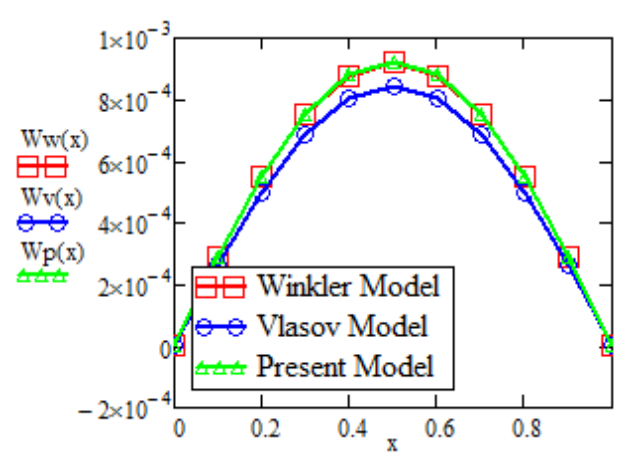

Fig. 7 Vertical displacement of the beam on elastic foundation (Modular Ratio $E_{0} / E=0.01$ )

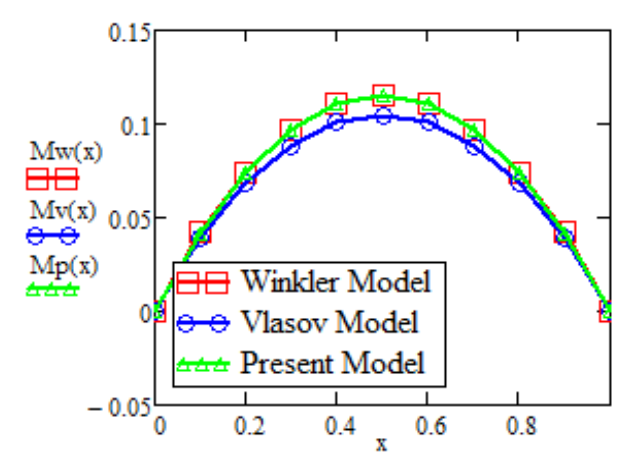

Fig. 8 Bending moment of the beam on elastic foundation (Modular Ratio $E_{0} / E=0.01$ )

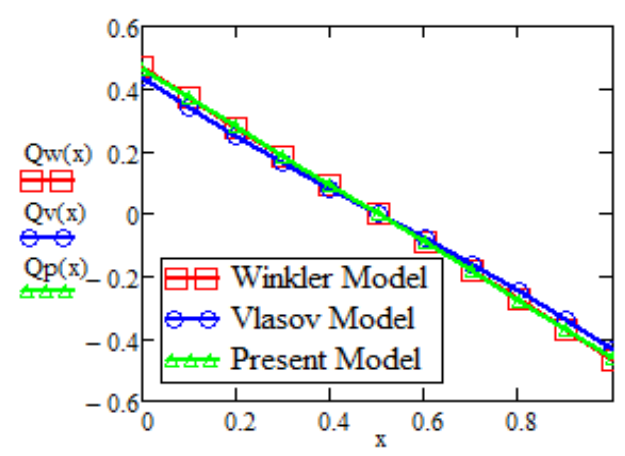

Fig. 9 Shear force of the beam on elastic foundation (Modular Ratio $E_{0} / E=0.01$ )

The results of the reactive pressure of the elastic foundation are shown in Figure 10.

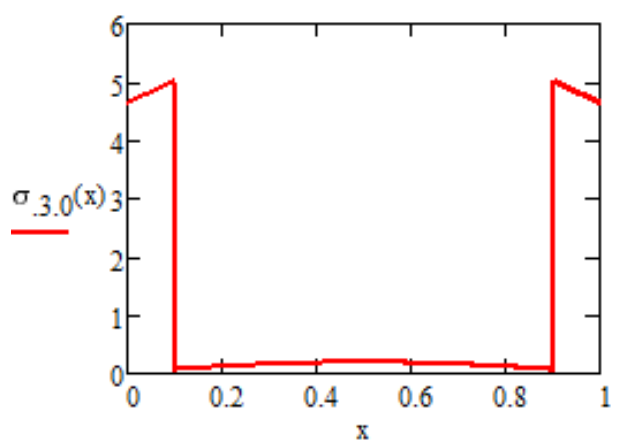

Fig. 10 Reactive pressure of the elastic foundation (Modular Ratio $E_{0} / E=0.01$ )

\subsection{Example 2}

The vertically uniform load was chosen as $q=200 \frac{k N}{m}$. The physical and geometry parameters of the elastic foundations were deformation modulus $E_{0}=55 \mathrm{~Pa}$ and Poissons ratio $v=0.25$, depth $H=5 \mathrm{~m}$. A beam of length $\mathrm{I}=10 \mathrm{~m}$, width $b_{0}=1 \mathrm{~m}$ and height $h=5 \mathrm{~m}$, modulus of elasticity $E=20 \cdot 10^{5} \mathrm{~Pa}$.

For the purpose of evaluating the accuracy of the proposed method, the results are compared with Winkler and Vlasov models. Figures 11-13 show an excellent agreement between the proposed method and Winkler and Vlasov obtained results for the shown three models.

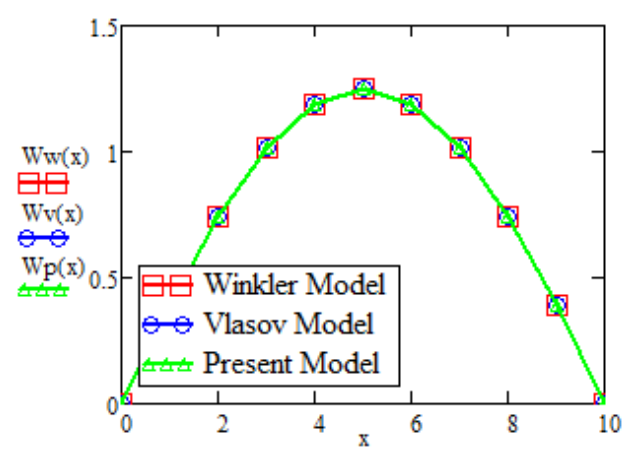

Fig. 11 Vertical displacement of the beam on elastic foundation

Thus, the mathematical model of a beam on elastic foundation in a simple form takes into account the influence of an elastic foundation and allows calculations using ready-made results for 


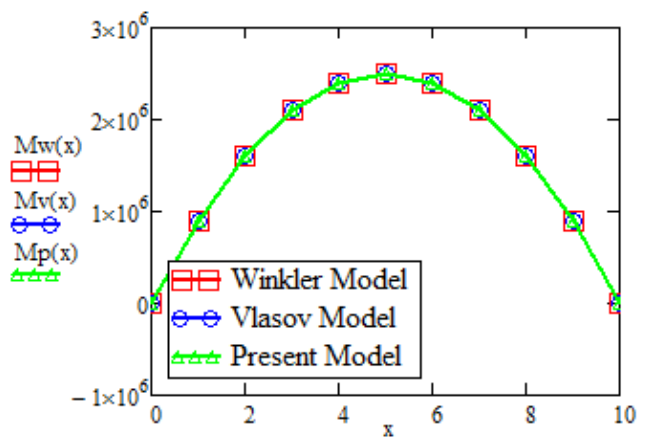

Fig. 12 Bending moment of the beam on elastic foundation

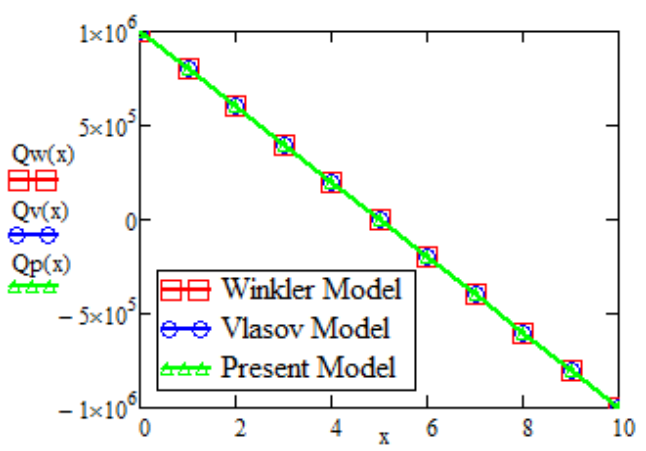

Fig. 13 Shear force of the beam on elastic foundation

beams without an elastic foundation.

The following recommendations are advanced as topics for future research: comparison of results from the new analytical model with full threedimensional behavior for the soil; study of the incorporation of the horizontal displacement in the soil; use of this present method for plate on elastic foundation.

\section{CONCLUSION}

The presented examples show some of the advantages of the suggested approach for an analytical solution of a beam on an elastic foundation. It gives opportunities for application of various loads at an arbitrary point or a region on the beam. Besides it can be applied for force or displacement boundary conditions at the beam's ends. The implementation of the approach into a computer system is simple and do not require special programing skills from the user. The presented solution can be implemented in every mathematical system that can solve ordinary differential equations. The obtained analytical solution can be used to analyze the influence of the different problem parameters on the structural behaviour.

\section{REFERENCES}

[1] Selvadurai, A.P.S. (1979). Elastic analysis of soil-foundation interaction. Elsevier Scientific, Amsterdam, Netherlands.

[2] Dutta, S.C., and Roy, R. (2002). A critical review on idealization and modeling for interaction among soil-foundation-structure system. Comput. Struct., 80(20-21), pp.15791594.

[3] Winkler, E. (1867). Theory of elasticity and strength, H. Dominicus, Czechoslovakia, Prague.

[4] Pasternak, P.L. (1954) On a New Method of Analysis of an Elastic Foundation by Means of Two Constants. Gosudarstvennoe Izdatelstvo Literaturi po Stroitelstvui Arkhitekture, Moscow, (in Russian).

[5] Filonenko-Borodich, M.M. (1940) Some Approximate Theories of Elastic Foundation. Uchenyie Zapiski Moskovskogo Gosudarstvennogo Universiteta Mekhanica, 46: pp.3-18. (in Russian).

[6] Vlasov, V.Z. and Leontiev, N.N. (1966) Beams, Plates, and Shells on Elastic Foundation. Israel Program for Scientific Translations, Jerusalem. (translated from Russian).

[7] Jones, R., and Xenophontos, J. (1977). The Vlasov foundation model. Int. J. Mech. Sci., 19(6), 317-323.

[8] Vallabhan, C.V.G., and Das, Y.C. (1988). Parametric study of beams on elastic foundation. J. Geotech. Engrg., 114(12), pp.2072-2082.

[9] Vallabhan, C.V.G., and Das, Y.C. (1991b). Modified Vlasov model for beams on elastic foundations. J. Geotech. Engrg., 117(6), pp.956-966.

[10] Akhazhanov S.B. (2015) Stress-strain state of an elastic half-plane. Mathematical methods and models in construction, architecture and design. Samara State University of Architecture, Building and Civil Engineering, Samara, pp.67-73. (in Russian).

[11] Tursunov K.A. (2009) Mechanics of bar structure. Karaganda, Izdatelstvo KarGU, (in Russian).

Copyright (C) Int. J. of GEOMATE. All rights reserved, including the making of copies unless permission is obtained from the copyright proprietors. 